\title{
«El hombre es tierra que anda». Los crianceros trashumantes del Alto Neuquén en perspectiva histórica, siglos XIX-XX ${ }^{1}$
}

Nicolás Padín ${ }^{2}$

\section{Resumen}

El artículo es el resultado de una investigación histórica que tiene por finalidad el análisis diacrónico de los crianceros trashumantes del Alto Neuquén, sus características, conflictos y devenir histórico. Tomando como punto de partida, la crítica a la actual celebración romántica de los crianceros desde los discursos políticos y mediáticos, el escrito se propone deconstruir el proceso de constitución de esta práctica, restituyendo la historicidad de sus transformaciones, permanencias y litigios con el poder político instituido.

El escrito se detiene en jalones clave del itinerario histórico de esta práctica social, económica y cultural secular, en tanto actividad que implica movimientos cíclicos de ascenso y descenso de los crianceros y sus animales, entre las tierras bajas, donde se sitúan las «invernadas» y las tierras altas de la Cordillera de los Andes y la Cordillera del Viento, donde se localizan las «veranadas». El artículo evidencia cómo los y las pastores/as trashumantes (productos históricos de una compleja hibridación indígena, criolla y chilena) sortearon hábilmente diversos desafíos que pusieron en entredicho su supervivencia, en una parábola que los situó desde un lugar

\begin{abstract}
The article is the result of a historical investigation whose purpose is the diachronic analysis of the transhumant breeders of Alto Neuquén, their characteristics, conflicts and historical evolution. Taking as a starting point, the criticism of the current romantic celebration of the crianceros from the political and media discourses, the writing proposes to deconstruct the process of constitution of this practice, restoring the historicity of its transformations, permanences and litigations with the instituted political power.

The writing stops at key milestones of the historical itinerary of this social, economic and cultural secular practice, as an activity that implies cyclical movements of ascent and descent of the crianceros and their animals, between the lowlands, where the «invernadas» are located and the highlands of the Cordillera de los Andes and the Cordillera del Viento, where the «veranadas» are located. The article shows how transhumant shepherds (historical products of a complex hybridization indigenous, Creole and Chilean) skillfully overcame various challenges that questioned their survival, in a parable that placed them from a place of mistrust,
\end{abstract}

\footnotetext{
1 Trabajo recibido el 30/10/2018. Aceptado el 22/12/2018.

${ }^{2}$ Universidad Nacional del Comahue. Director General de Patrimonio Cultural Inmaterial de la Provincia de Neuquén. Contacto: padinicolas@yahoo.com.ar
} 
de desconfianza, hasta en la actualidad, ser objeto de una fuerte invocación pública desde la perspectiva del patrimonio cultural.

Palabras clave: crianceros -trashumancia pastoril - arreos - Neuquén until today, be the object of a strong public invocation from the perspective of cultural heritage.

Keywords: crianceros -small transhumant herd -drive -Neuquén

\section{Introducción ${ }^{3}$}

El presente trabajo plantea tomar como punto de partida la constatación de que la ganadería trashumante desarrollada por pequeños productores rurales, autodenominados crianceros, en el norte de la Provincia de Neuquén, lejos de ser una reliquia cultural del pasado, posee una fuerte vitalidad en pleno siglo XXI. La persistencia de las veranadas y las invernadas de los crianceros y sus rebaños de animales que surcan las Cordilleras del Viento y de los Andes o, en otras palabras, de variaciones temporales, espaciales y estacionales (Silla, 2010), de una peculiar gastronomía popular en torno del chivo criollo, de singulares manifestaciones musicales como las expresadas por las cantoras campesinas y de diversas festividades religiosas (Fiesta de San Sebastián en las Ovejas y Fiesta del Regreso del Veranador en Barrancas, entre otras) dan cuenta de un rico universo económico, social y cultural que se ha mostrado refractario al avance de la modernidad capitalista. O, dicho de otro modo, evidenciando una gran capacidad de adaptación a las interdicciones sociopolíticas y económicas. Estas seculares pugnas de los y las crianceros/ astrascendieron las adversidades de la naturaleza, como los avatares de las constricciones políticas y del mercado. Si bien se vislumbra una tendencia a la restricción de la actividad de los crianceros trashumantes, en ámbitos progresivamente delimitados, no deja de ser notable su persistencia frente a políticas cambiantes que pusieron en peligro esta práctica, constituyendo algunas de las claves que permiten comprender su capacidad de adaptación a la aculturación y al capitalismo.

\footnotetext{
${ }^{3}$ Se agradece la inestimable colaboración del Señor Mariano Basso en la búsqueda de bibliografía y de documentos históricos imprescindibles para el análisis diacrónico de los crianceros trashumantes del norte de Neuquén. Asimismo, agradezco la gentileza del fotógrafo Agustino Mercado por la cesión de la última fotografía que consta en el artículo.
} 
La palabra trashumancia proviene del prefijo latino tras: «de un lado a otro» y la raíz de la vocablo latino humus: «tierra». En ese sentido, la antigua sentencia andina que Atahualpa Yupanqui transformara en poesía se acopla a la perfección a los destinos en movimiento de los crianceros y el célebre cantautor: el hombre, la tierra, el camino... en fin, «el hombre es tierra que anda», el hombre es tierra animada. ${ }^{4}$ Estas coordenadas son una constante en el periplo secular que anualmente remontan los trashumantes hacia las tierras altas de la cordillera. En este marco, el artículo se propone desandar el camino realizado por los veranadores del Alto Neuquén revisandoc ómo, entre noviembre y abril de cada año, columnas ondulantes de hombres y mujeres, caballos, chivos, vacas, mulares y perros continúan su marcha ancestral en pleno siglo XXI hacia el corazón de los Andes y el viento.

Realizando movimientos cíclicos de carácter vertical, entre las tierras bajas, áridas y semiáridas, situadas en las invernadas y las tierras altas de la Cordillera de los Andes, donde se asientan las veranadas en busca del alimento para los animales (mayormente ganado caprino) que brindan las pasturas del estío, el trabajo trashumante constituye una forma productiva particular, que se presenta en diversas zonas del país, especialmente en la región cordillerana, desde el sur de Mendoza hasta la provincia de Santa Cruz. Se vislumbra con mayor intensidad en el Alto Neuquén, es decir, a partir del centro y norte de esta provincia, zona que, en consecuencia, será objeto de nuestras pesquisas. De modo predominante, la actividad trashumante involucra aproximadamente allí a 1.500 productores de ganado menor, distribuidos mayoritariamente en los Departamentos Minas, Chos Malal y Norquín. El trayecto de ascenso hacia las veranadas demora temporalmente, en los casos más prolongados, alrededor de 25 a 30 días, con picos de extensión que superan los 200 kilómetros, en más de 100 huellas de arreo que delinean la subida hacia diferentes pisos altitudinales. ${ }^{5}$ Durante la invernada los animales permanecen en mesetas y valles bajos, alejados de las zonas nevadas. Afines de la primavera se realizan los desplazamientos hacia las verana-

\footnotetext{
${ }^{4}$ Runa allpacamaska: el hombre es tierra que anda. Antigua y poética sentencia andina recogida por Atahualpa Yupanqui (1948).

${ }^{5}$ De acuerdo a información del año 2014 se registran huellas de arreo con una longitud reducida como la trayectoria del Callejón de Haychol de 9,9 Km, hasta una extensión máxima de 134 km como la de Sierra Negra-Buta Mallín-Costa del Colorado (Ver Ley Provincial 3016/2016 de Trashumancia de la Provincia de Neuquén).
} 
das, es decir, los campos altos de las faldas cordilleranas, situados por encima de los 1500 metros sobre el nivel del mar, en los que al derretirse la nieve se accede a las pasturas renovadas. Hacia el mes de abril comienza el descenso, repitiéndose el ciclo. Las únicas zonas que permanecen habitadas durante todo el año son los sectores de menor altitud, cercanos a los principales ríos. Este esquema económico implica un patrón de asentamiento caracterizado por la movilidad estacional, en el que las familias deben contar durante el año con dos y hasta tres espacios habitaciones: de invernada, de veranada y una intermedia denominada de primavera (Fernández, 1965).

\section{Mapa $N^{\circ}$ 1. Crianceros trashumantes de Neuquén - Despliegue geográfico}

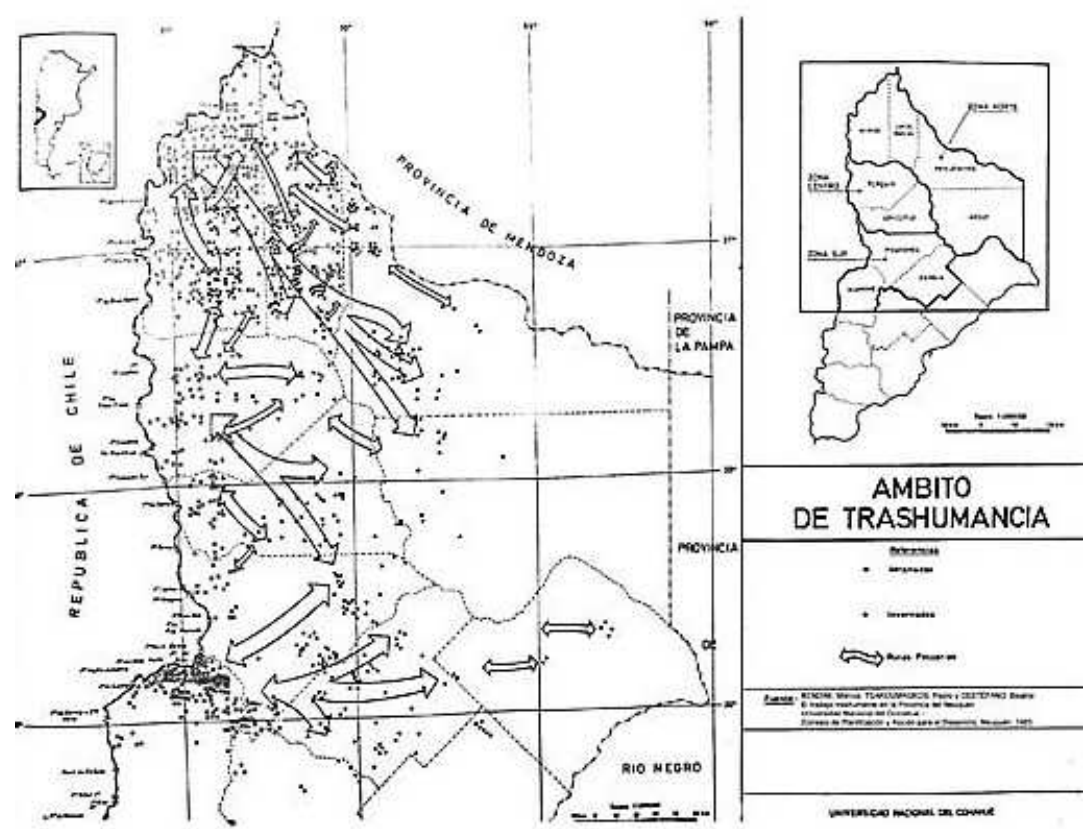

Fuente:Bendiniet al.(1985)

¿Acaso estos movimientos pendulares de los crianceros constituyen el corolario ineludible de las condiciones agroecológicas en el que se 
desenvuelven? Indudablemente la respuesta puede inclinarse por la negativa: la dialéctica entre los agentes sociales y el medio adquiere en esta zona septentrional de la Patagonia argentina altas dosis de ingenio y adaptación. La gran diversidad fisiográfica del territorio neuquino aparece claramente manifiesta a través de gradientes que implican la disminución del relieve y de las precipitaciones en dirección oeste-este y sus efectos directos sobre la vegetación. La conformación de un paisaje que, en ese mismo sentido, se modifica desde estructuras orográficas complejas, como la Cordillera de los Andes y la Cordillera del Viento en el occidente y centro, hasta la simplificación que refleja la meseta patagónica oriental, generó significativos efectos, condicionando las características del asentamiento humano y de la actividad económica ganadera históricamente dominante, incluida la actividad de los crianceros (Bandieri, 2012). Esta práctica, desarrollada desde las etapas de ocupación indígena del espacio, muy concentrada en las áreas ante cordilleranas, permitía, junto a la presencia de innumerables valles que facilitan el cruce de los Andes en este sector, las relaciones socio-económicas con el sur de Chile, transformando al área fronteriza en un espacio social de larga duración, alta complejidad y densas relaciones económicas, sociales y culturales. No obstante, las propuestas que orientan la carga explicativa en el influjo de los condicionantes geográficos de las prácticas trashumantes han sido numerosas, permeado subrepticiamente los análisis de la actividad, teniendo duraderas resonancias. Un ejemplo revelador, especialmente por el fuste intelectual del autor, puede servirnos para sostener nuestro argumento: a mediados del siglo XX Federico Daus, padre de la geografía argentina, ${ }^{6}$ pese a la excelente descripción geográfica y etnográfica que realizó de la «trashumación de montaña» neuquina, caracterizó a la actividad criancera como parte de un «vaivén espontáneo» donde los actores rurales se acoplan, mimetizándose a los ritmos de la

\footnotetext{
${ }^{6}$ Daus fue una figura clave en la constitución del campo profesional de la geografía en Argentina. Ya en 1933 constituía una de las caras visibles de la disciplina en el país, al convertirse en intermediario entre el secretario general de la Unión Geográfica Internacional (UGI), el geógrafo francés Emmanuel De Martonne, y los funcionarios del gobierno de Justo. Ello le valió la designación como secretario del Comité Nacional de Geografía, órgano dependiente del Ministerio de Defensa que constituía la representación oficial de la UGI en el país. A partir de estas posiciones institucionales, Daus fue cobrando creciente influencia en el campo de la enseñanza media de la geografía, alcanzando los principales cargos institucionales de la disciplina: presidente de la Sociedad Argentina de Estudios Geográficos (GAEA) y de decano de la Facultad de Filosofía y Letras de la Universidad de Buenos Aires (Quintero, 2002).
} 
naturaleza y los animales, relativizando su constitución como constructo histórico y cultural. Es claro que Daus no subestimó la dialéctica entre los agentes sociales y el ambiente y las modulaciones que se producen en función de las valorizaciones que se producen histórica y socialmente, de acuerdo a diversos esquemas de producción. Vale la pena reproducir in extenso el análisis de Daus y de lo que denomina en tono poético como el «llamado de la montaña»:

La trashumación en zonas de montaña consiste en el traslado estacional, en masa, de los rebaños conducidos por los pastores que marchan también, con todo su arreo y haber doméstico, hacia las dehesas de montaña para pasar el verano, es decir a la veranada. El hábitat del invierno, al cual se regresa oportunamente, son las planicies pedemontanas de moderada altitud, o valles bajos en el mismo ámbito de la montaña y en ciertos casos comarcas alejadas de las montañas hasta más de un centenar de kilómetros: se denominan invernadas a estas estaciones de invierno. La trashumación es un vaivén espontáneo que se cumple como un ajuste estricto a las condiciones naturales que lo regulan. El determinismo geográfico del fenómeno queda afirmado por la espontaneidad y la similitud con que ha nacido y perdura en todas las comarcas donde se registra... La trashumación es un acto de ajuste de la vida pastoral a ciertas exigencias de la naturaleza, tiene rasgos fundamentales de hecho natural (Daus, 1948, p. 383).

La orientación a pensar la actividad por parte de Daus, como otros autores posteriores (Bestard, 1996) como la consecuencia de una «inclinación natural», evidenciada en el comportamiento de los propios animales encuentra una prueba irrefutable en la observación participante en el campo: efectivamente, los animales manifiestan el afán de comenzar el periplo hacia la veranada y retornar a la invernada cuando al final de cada estación dejan de comer en los campos, agolpándose en las tranqueras por donde se inicia el viaje, en una perfecta adaptación al ambiente.

\section{Los crianceros neuquinos en el altar de la neuquenidad}

Si bien es indudable la pregnancia a la tierra de estos actores rurales del norte neuquino es interesante revisar la presente celebración ro- 
mántica de los crianceros como uno de los componentes centrales de la nenquenidad. La construcción de una identidad neuquina estuvo fuertemente relacionada con el contexto histórico del pasaje de Neuquén de territorio nacional a provincia, decretado en 1955. Como señala García (2008), en la etapa que comenzó con la provincialización -y que se afianzó entre 1966 y 1976- se dio un proceso de búsqueda de la construcción del pasado de la región, de una memoria narrada desde el Estado que sería el sustento de la identidad neuquina, transformándose en el núcleo ideológico organizador del proyecto político del partido político provincial, el Movimiento Popular Neuquino. En este sentido, desde el Estado provincial se impulsó la formación de un entramado en el que historiadores, militares, miembros del gobierno y otros intelectuales se dedicaron a la elaboración de una historia, a la creación de una memoria oficial para la provincia. La principal herramienta de creación y difusión de la nenquenidad que se buscaba construir fue la Junta de Estudios Históri$\cos (\mathrm{JEH})$. En línea con los requerimientos de quienes protagonizaron el golpe de Estado de 1966 a nivel nacional, buscaron organizar una unidad entre el pasado y el presente a partir de la reconfiguración del campo político y del campo cultural. La figura del primer médico patagónico, el Dr. Gregorio Álvarez tuvo una relevancia axial en el período al aglutinar -a través de diversas instituciones como la Casa Neuqueniana y la mencionada JEH- al núcleo de intelectuales orgánicos que construirían los basamentos simbólicos «genuinos» de la identidad neuquina. Esta «historia oficial» se constituyó a través de una narrativa que se manifestaba en discursos políticos, conferencias académicas, iconografía, estatuas, monumentos, museos, denominación de calles y en el sistema educativo. Efectivamente, como lo expresan Duimich y Lizárraga (2017), «la neuquinidad no es sólo un discurso político, sino aquello que lo constituye: una construcción estética e identitaria hecha de naturaleza y cultura; de pasado y presente; de inclusiones y exclusiones. Es la (re)construcción permanente del pasado desde el poder y desde la resistencia» (p. 42).

Sin embargo, la construcción de una narrativa «legítima», en la imbricación entre el Estado provincial y la intelectualidad alvazeriana, no clausuró la emergencia de litigios entre distintas narrativas acerca del pasado, en disputa por la definición de la «esencia neuquina». Desde lanarrativa oficial, era necesario continuar con las tareas «civilizatorias» iniciadas con la «Conquista del Desierto» y que tuvieron como uno de los objetivos dilectos a los mapuches. No obstante, la historiografía re- 
gional ha pasado por alto cómo los crianceros trashumantes del norte neuquino atravesaron tentativas similares de incorporación subordinada a la «esencia neuquina». En este sentido, es interesante plantear el interrogante sobre las condiciones de admisión en el ingreso al panteón de la neuquenidad de los sectores subalternos, específicamente los crianceros. En primer término, fue necesario un largo y tortuoso proceso de sublimación étnica, nacional y de clase por el cual los crianceros tuvieron que realizar diversos desmarcajes identitarios: como pehuenches y mapuches primero y luego como chilenos. Una vez desprovistos, desde la construcción de la narrativa oficial, de todas aristas controvertidas y transformados en criollos y argentinos, una vez diluida su reivindicación histórica a la tierra, serían incorporados en tanto reserva «histórico-cultural» de los neuquinos. Con esta incorporación a la neuquenidad en tanto construcción política, social e histórica de un «nosotros» neuquino basado en la atribución de un pasado en común, una idiosincrasia y un componente «nyc» (nacido y criado), propio de la constitución de una comunidad imaginada (Anderson, 2006), los crianceros trashumantes se han constituido a partir de las últimas décadas del siglo XX en una de las últimas incorporaciones. Esto ha sido a través de imágenes estereotipadas, desde la óptica del exotismo, que esencializan sus atributos y descontextualizan su secular pregnancia y lucha por la tierra. Vinculado a ello, la importancia dada al universo sociocultural de los crianceros se relaciona con una oposición subrepticia entre la ciudad de Neuquén, centro político, social y económico de la provincia y de la Norpatagonia, con un componente demográfico aluvional muy fuerte vinculado a ser el espacio de recepción de flujos inmigratorios y un «interior» que sería la reserva cultural de la identidad provincial, de una neuquenidad asociada a una matriz telúrica, frente a la modernidad y «cosmopolitismo» de la capital.

Se propone, en consecuencia, la realización de un recorrido que desmitifique la figura de los crianceros del Alto Neuquén y que restituya la historicidad de sus transformaciones, permanencias y litigios con los poderes del Estado, el mercado y sus agentes. Para ello, analizamos las modalidades de funcionamiento socioeconómico de las sociedades indígenas, pasando por el punto de inflexión que significaron las campañas militares de anexión de la Patagonia a fines del siglo XIX por parte del Estado nacional argentino, denominada equívocamente como «Conquista del Desierto» y la reestructuración de la actividad, deteniéndonos en el cierre de las fronteras internacionales y un período de fuerte descenso de la actividad y carestía entre 1940 hasta la década de 1970, donde es posi- 
ble vislumbrar movimientos contradictorios que significan una tendencia a la transformación de la actividad de la ganadería trashumante y diversas medidas gubernamentales que tienen por objeto revitalizar y apuntalar la actividad.

\section{Por las huellas del arreo}

Desde la arqueología y la historia existe un consenso relativo de ubicar la antigüedad de la trashumancia en 2.000 años aproximadamente. Siguiendo rutas perfectamente determinadas, las parcialidades indígenas del área pampeana y patagónica alternaban su localización entre sitios de invernada y veranada para un mejor aprovechamiento en la caza de animales, utilizando refugios rocosos en invierno o toldos transportables hechos de pieles de guanaco, cuando el clima era más benigno, controlando los territorios de caza, los cursos de agua y las áreas de asentamiento. Posteriormente, ha sido posible constatar en Neuquén, a partir de información arqueológica y etnohistórica, la existencia durante los siglos XVIII y XIX de un particular sistema de infraestructura de sitios con recintos pircados, relacionados con el tráfico de hacienda hacia Chile y destinados a un adecuado manejo de territorios (Goñi, 1987; Varela y Biset, 1993).

A partir del siglo XVIII, el contacto con los colonizadores europeos generó importantes transformaciones en las sociedades originarias. La adopción del ganado, especialmente el caballo, transformó progresivamente a los grupos indígenas en pastores ecuestres, ganaderos y comerciantes. El traslado de animales fue abarcando un ancho corredor interregional entre las pampas rioplatenses y la araucanía chilena, que implicaba un adecuado aprovechamiento de los valles de invernada y veranada con un estricto control de las aéreas irrigadas y salinas ubicadas en las travesías, ricas en pasturas en tramos específicos, capaces de alimentar abundantes cantidades de ganado. En una sociedad de ganaderos y comerciantes, se daba una estrecha relación entre los patrones económicos y el manejo del espacio, donde la utilización de los recursos naturales no obedecía a la lógica indeterminada de la errancia. Contrariamente, los campos de pasturas, las aguadas y la cercanía a las rutas y pasos fueron factores determinantes en la distribución de la población. Las tolderías no se localizaban al azar; es probable que cada grupo familiar tuviera un sitio prefijado para su campamento. En consecuencia, los 
campos cordilleranos de la Norpatagonia resultaban excelentes para el acondicionamiento del ganado antes de someterlos al esforzado cruce de los Andes. Las parcialidades indígenas asentadas en la cordillera fueron, por su privilegiada situación geográfica, una pieza clave en este complejo mundo de relaciones construido alrededor de la frontera con el blanco. Estos grupos, de distintos orígenes y alta complejidad étnica, oficiaban de excelentes intermediarios entre el ganado proveniente de la región pampeana y el mercado de consumo de la entonces Capitanía General de Chile.

La economía de las tolderías se organizaba alrededor de la cría del ganado que sería comercializado en Chile. Por ello era imprescindible contar con buenos pastos, agua suficiente y potreros naturales que permitieran albergar los rodeos. La búsqueda de pasto, agua y sal, sumado a las variaciones estacionales, determinaban el traslado de los campamentos a las zonas altas en primavera y verano. Al llegar el invierno, con las primeras nevadas, las tolderías descendían a establecerse en los valles bajos y abrigados de las invernadas (Bandieri, Favaro y Morinelli, 1993). Sin embargo, sería equívoco visualizar esta movilidad estacional en términos de nomadismo. Existía una movilidad temporal ajustada a los ciclos estacionales donde se desarrollaba una utilización de los recursos naturales disponibles, como aguadas y pasturas. En este sentido, es esclarecedor lo manifestado por el naturalista alemán Poeppig al afirmar que «cuando se derrite la nieve, suben a puntos cada vez más elevados de la montaña, pero sin salirse de un determinado distrito, que ha pertenecido desde tiempos inmemoriales a su tribu» (Villalobos, 1989, p. 57).

\section{«Fijar los cuerpos». Los crianceros entre la «Conquista del Desierto» y el cierre de las fronteras}

Hacia fines del siglo XIX el avance y consolidación del EstadoNación en Argentina y la demanda de materias primas y alimentos por parte de los países industrializados, en el marco de la ricardiana división internacional del trabajo, volcó definitivamente a la economía argentina a la producción agroexportadora. La consecuencia inmediata fue la necesidad de incorporar tierras para la expansión de la ganadería extensiva, generando la intensificación de la disputa territorial entre las parcialidades indígenas y la oligarquía terrateniente pampeana, que finalizó con la expropiación y exterminio de las primeras y la ocupación de la Patagonia 
por parte del Estado nacional, a través de las campañas militares de conquista de la región, conocidas tradicionalmente con la equívoca denominación de «Campañas al Desierto». ${ }^{7}$ De esta manera, la hacienda cimarrona, base económica de las sociedades indígenas y el producto fundamental de su comercio, vio seriamente afectada sus posibilidades de reproducción.

Como resultado del reparto territorial surgieron terratenientes latifundistas, generalmente absentistas, que se apropiaron de los mejores suelos para la actividad ganadera en la Patagonia. Por otro lado, en las enormes extensiones de tierras fiscales, de inferior calidad, se asentaron crianceros, ocupantes sin título de ambos lados de la cordillera, con sus respectivas familias y pequeñas majadas de animales para su subsistencia, entre quienes se encontraban los pobladores originarios sobrevivientes, criollos pobres y un considerable contingente de chilenos que circulaban en el espacio fronterizo (Bandieri, 2005). En este nuevo contexto, la antigua trashumancia pastoril realizada por las sociedades indígenas se ajustó a las nuevas coordenadas de poder y organización territorial bajo la convergencia de un proceso de hibridación que nucleó a los sectores populares rurales y en el que se destacaron pehuenches y mapuches, chilenos y criollos. El clivaje étnico dejó de ser un eje de adscripción de identidad clave, quedando subsumido en una heterogénea amalgama que comenzó a priorizar la pertenencia como crianceros, sublimando las diversas pertenencias identificatorias previas a la «Conquista del Desierto». ${ }^{8}$

Hacia diciembre de 1893, en Chos Malal, capital del recientemente creado territorio nacional del Neuquén, veía la luz el semanario Neuquén que, en la pluma del fiscal del Juzgado Letrado, Francis Albert, tuvo a su cargo la preparación de la primera editorial que expuso las directrices del gobierno nacional y de sus clases dirigentes para la región. Con el explícito título «nuestros propósitos», Albert delineó los

\footnotetext{
${ }^{7}$ En el imaginario hegemónico de la época el «desierto» era sinónimo de vacío de civilización, en el marco de la clave sarmientina de civilización o barbarie. Claramente, los indígenas eran considerados el epítome del salvajismo, justificando, en consecuencia, su exterminio, expropiación o aculturación.

8 A partir de allí se produce una criollización de la actividad trashumante que genera un desplazamiento de su clivaje étnico, invisibilizando su componente indígena, tanto en términos de legado histórico, como de una práctica realizada por innumerables comunidades mapuches de la región en la actualidad como por ejemplo la Comunidad Huayquillan, en Colippilli.
} 
ejes programáticos del nuevo orden social trazando una descripción edénica del «desierto» anexado a la Nación como tierra de promisión y alertando, a su vez, sobre las dificultades que esta enorme empresa implicaba por el carácter «nómade» de su población y la necesidad perentoria de fijarlos a la tierra y a la nación. Al respecto Albert decía:

Tierras vírgenes que se extienden en valles y montañas de exuberante vegetación y que el arado primitivo surcó superficialmente arrancándoles sorprendentes cosechas; aguas ricas y cristalinas que en su eterna corriente fecundan el suelo en todas las direcciones; bosques de árboles gigantescos que ofrecen inmejorables materiales de construcción... productos minerales abundantes que, cansados de dormir en el seno de la madre común, grietan su cárcel para exhibirse ante los ojos del viajero, protesta elocuente de nuestra desidia. Sin embargo, la población es nómade en su casi totalidad, porque le falta el estímulo del arraigo, la facilidad de adquirir pequeños lotes de tierra, y en estas condiciones es un elemento transitorio que nada de provecho deja en pos de sí, más que el trabajo inconsciente de la vaca que pastorea (Semanario Nenquén, 1893, p. 1).

La editorial inaugural del territorio neuquino además de brindar una descripción apologética de las potencialidades del territorio, establecía las prioridades de la agenda de gobierno en torno a la necesidad de arraigar a la población «nómade» neuquina en general y a los pequeños productores rurales trashumantes, en particular. Al ser la ganadería trashumante la principal actividad económica de la región, tempranamente las primeras autoridades políticas del territorio nacional de Neuquén implementaron variadas medidas tendientes a su intervención, que influyeron fuertemente en la actividad. Las exigencias de fijación a la tierra de una población rural fuertemente móvil y las necesidades de captación fiscal fueron objetivos prioritarios de los noveles gobernadores territorianos. Al respecto, Olascoaga, primer gobernador de Neuquén, en su correspondencia periódica con las autoridades nacionales advertía:

[el] desarrollo constante de población que se opera en estos parajes la que se establece arbitrariamente entre las montañas y escondidas quebradas lo que más tarde será causa de grandes males por ser numerosas las familias que se diseminan en todo el territorio en campos de propiedad particular y fiscal, allí donde un retazo de tierra de labores puede ofrecerles el sustento y facilidad para criar sus escasos rebaños... los pobladores que acuden de la República veci- 
na... levantan una humilde choza entre las sierras contentándose a sembrar cuanto más dos cuadras de trigo para su propio consumo. ${ }^{9}$

Inmediatamente asentadas las autoridades locales en representación del Estado nacional, la fijación a la tierra de una población rural dedicada a la pequeña ganadería trashumante fue una de las preocupaciones nodales en las últimas décadas del siglo XIX y de la primera mitad del siglo XX en la zona centro y norte de Neuquén. Se podría afirmar que los cimientos del nuevo orden social, económico y político establecido después de las campañas militares contra las sociedades indígenas de la Patagonia tuvieron como pilares fundamentales la instalación de agencias estatales claramente rudimentarias, como la escuela y la policía, pero que marcan la orientación de sus elites dirigentes y una tendencia que fue incrementándose conforme avanzaron las décadas del siglo XX. Especialmente hacia 1930-40, cuando la gendarmería nacional logró efectivizar el cierre de la frontera internacional con Chile. Claramente, no se desarrolló una intervención unidireccional, «desde arriba», de las agencias estatales sobre los crianceros trashumantes, implicando un proceso homogéneo de restricción de la movilidad y de aculturación. No obstante, los deseos de control y de regulación estatal de la actividad trashumante y de sus actores, los crianceros, constituye una marca de agua de todo el período. Puede que un ejemplo ilumine lo dicho. Bajo la gestión del segundo gobernador territoriano (1890-1894), el general Sócrates Anaya, alcanzó uno de los puntos más álgidos la pulsión de vigilancia y control hacia los pequeños pastores trashumantes neuquinos. Al respecto, las crónicas mencionan en tono crítico cierta obsesión organizadora que le llevaba a imponer al representante del gobierno nacional medidas que estaban más allá de la voluntad del gobierno nacional. Así, entre muchas cosas, «dispuso por Decreto en qué fecha de la primavera sería permitido llevar los ganados trashumantes a las 'veranadas' y en qué fecha podrían retornar a las 'invernadas', en otoño». ${ }^{10}$ Pese a la extravagancia de la medida y a la imposibilidad manifiesta de poder efectivizarla, por no contar con los recursos materiales para llevarla a cabo, especialmente teniendo en cuenta la endémica carencia de fuerzas policiales en un dilatado territorio, la pretensión de regular de un plumazo, por un

\footnotetext{
${ }^{9}$ Archivo Histórico de la Provincia de Neuquén (AHPN), Nota $\mathrm{N}^{\mathrm{o}} 18$ al Ministro del Interior de la Nación. Libro Copiador IV. Chos Malal, 06/1890.

${ }^{10}$ Nenquenia, (1953), p. 4.
} 
acto gubernativo, una actividad que implicaba el movimiento estacional de miles de familias en una escala regional que involucraba significativas extensiones de kilómetros, evidencia la preocupación permanente de las autoridades por regularla. En este sentido, podríamos pensar la relación entre las agencias estatales y los crianceros no tanto como un proceso de penetración inexorable de los atributos de la estatalidad hacia los sectores subalternos, que pasivamente verían restringida su actividad en términos progresivos. Más bien, se desarrollaron complejos ámbitos de intersección entre la voluntad estatal por constituir un orden social, donde la fijación a la tierra de los actores rurales fue prioritaria y los espacios de agencia, adaptación y reinvención tuvieron mayor plasticidad y autonomía de lo que la historiografía suele reconocer.

\section{«Se acata, pero no se cumple». Estrategias crianceras de autonomía}

Emulando, las antigua estrategia colonial de «acatar, pero no cumplir» las disposiciones reales en suelo americano, los crianceros trashumantes del Alto Neuquén fueron objeto de una batería de medidas que buscaban controlar y fijar a la tierra sus actividades productivas, frene a las cuales desarrollaron un repertorio variado de estrategias autónomas de actuación. Efectivamente, la queja por la naturaleza de una «población que se haya muy diseminada en el territorio, no siendo estable» ${ }^{11}$ evidenciada, por ejemplo, en el elevado grado de ausentismo escolar y las imposibilidades de imposición tributaria por su carácter móvil, dan cuenta de una serie de manifestaciones a las autoridades nacionales que se sucedieron durante la primera mitad del siglo XX como una insistente letanía en términos de aspiraciones gubernamentales, aunque alejadas de una materialización real. Los pedidos permanentes de construcción de infraestructura, como puentes y caminos, así como la contratación de maestros y policías constituyen una constante del período. Puede que un pasaje del Gobernador Rawson (1894-1899) dé cuenta de lo mencionado: «nadie tiene derecho de ocupar con hacienda los campos de propiedad fiscal, sin abonar el arrendamiento que las disposiciones legales establecen». ${ }^{12}$ Diversas normativas con idéntica intencionalidad evidencian

\footnotetext{
${ }^{11}$ AHPN. Libro Copiador 3, Nota al Presidente del Consejo Nacional de Educación, Chos Malal, 1892.

12 AHPN. Libro Copiador 14, folio 10, 1893.
} 
cómo este tipo de disposiciones eran simplemente desoídas por los crianceros. La utilización de tierras fiscales para pastaje y la elusión tributaria fueron, más que una excepción, lo usual. La búsqueda de fuentes de financiamiento tuvo como referencia obligada el «cobro de talajes», que consistía en otorgar derechos de pastaje a los veranadores en tierras fiscales. Éstos eran en su mayoría de nacionalidad chilena, suerte de hinterland histórico del país transcordillerano, durante buena parte de la etapa colonial, hasta la década de 1930-40 cuando se produjo el cierre efectivo de la frontera internacional con ese país.

Sin embargo, pese a no haber sido registrada una oposición abierta a las nuevas disposiciones del poder nacional, existieron modalidades capilares de adaptación y resistencia de los pequeños productores rurales trashumantes, vinculados al tipo de prácticas consuetudinarias antes mencionadas, donde el rechazo pasivo y sutiles formas de evasión fueron las más distintivas, yendo desde la ocupación de tierras públicas sin autorización gubernamental, el abigeato, la evasión al servicio militar, el ausentismo escolar de hijos e hijas de los crianceros, como la fuerte resistencia a eludir el pago de gravámenes por la utilización fundiaria (Perren, 2010). Es interesante detenernos en la figura del abigeato por su importancia clave en una sociedad de pastores como la analizada. Al respecto, el robo de ganado y la proximidad de la frontera con Chile originaban:

(...) frecuentes denuncias sobre robos de haciendas... Los numerosos boquetes de los andes ofrecen pronta salida a los malhechores... y la ausencia de personal... causa de que muchos delitos queden impunes... la grande afluencia de población que año a año crece de una manera extraordinaria, como asimismo el notable aumento de la riqueza pecuaria que concurre de la provincia de Buenos Aires, Pampa Central y Río Negro han aumentado las atenciones de la policía del territorio... y en mérito de la grande extensión de la cordillera que la limita con la parte de Chile y que presta fácil ingreso hacia esa República. ${ }^{13}$

Los frecuentes robos de ganado, el establecimiento sin autorización de la población rural entre montañas y quebradas, de propiedad privada y mayormente fiscal, son algunas de las manifestaciones de un variado repertorio de acción situado en la intersección entre el desplie-

${ }^{13}$ AHPN. Libro Copiador $\mathrm{N}^{\circ} 4$, Nota $\mathrm{N}^{\circ} 16$ al Ministro del Interior de la Nación, 1890. 
gue incipiente de la autoridad estatal y formas consuetudinarias de autonomía, cristalizadas históricamente, que tenían como figura paradigmática al criancero, de difícil erradicación por los poderes públicos. Ello nos alerta sobre la existencia de dispositivos microscópicos que permiten comprender cómo los pequeños crianceros buscaron sortear las diversas interdicciones que el orden estatal comenzaba a crear y la fuerte sospecha y estigmatización que empezaron a sufrir por sus «resabios» indígenas y chilenos. En este sentido, las reflexiones de Michel Onfray (2016) nos parecen significativas para repensar la genealogía del trashumante y su relación con los tropismos nómadas. El filósofo francés nos advierte que los nómadas (los trashumantes y las «gentes en movimiento» también) siempre han inquietado a los poderes, son incontrolables, en tanto elección libre de fijar, de registrar y de pagar impuestos; en suma, de controlarlos. «La oposición arquetípica, sedentario-nómada hunde sus raíces en la Biblia: Caín y Abel. Estos hermanos viven una tragedia, el primero agricultor, el segundo pastor... A partir de ese momento iniciático, todas las ideologías dominantes han pretendido ejercer su control, su dominación, entiéndase su violencia, sobre el nómada como arquetipo y sobre todos aquellos sujetos y grupos humanos inclinados al movimiento» (pp. 15-16). De igual manera el capitalismo sin más condena la errancia, la ausencia de una morada fija y previsible, ya que se trata de sujetos que no son fácilmente asimilables al poder y al mercado.

Un testimonio elocuente de la importancia de la ganadería trashumante en Neuquén, pese a la desestructuración del modelo económico indígena, nos lo ofrece el cronista salesiano Lino Carbajal, en su libro Por el Alto Neuquén... del año 1906. En su camino al Volcán Domuyo Carbajal brinda una exhaustiva descripción de los veranadores, que merece ser reproducida en extenso:

Es cosa de ver marchar estos veranadores con todos sus pertrechos y haciendas. En todo el territorio de Neuquén, a mi juicio, son más de 15.000 personas las que van a las veraneadas, conduciendo 15.000 vacunos, 50.000 ovejas, 25.000 cabras, 10.000 caballos y $300 \mathrm{mu}-$ las. Es un verdadero éxodo, y durante el mes de diciembre, no se camina en ninguna dirección hacia las cordilleras, sin hallar estas extrañas colonias ambulantes... donde van familias, gallinas, perros, gatos y hasta los loros sobre los hombros de las mujeres. Cuando se pone en marcha, es indescriptible el vocerío, de las vacas y terneros, de las cabras y ovejas, de los potros y yeguas, de las gallinas, patos, perros, gatos y muchachos que lloran... iQué infernal gritería! Si: 
esto debe parecerse al éxodo de los judíos hacia su tierra prometida (Carbajal, 1906, pp. 93-94).

Claramente, pese a las campañas militares de anexión de la Patagonia y al reparto territorial realizado por el Estado nacional, el Alto Neuquén continuaba siendo un espacio de exuberancia asimilable a una «tierra prometida». Si bien sería exagerado hablar de una belle époque, las primeras décadas del siglo XX les permitieron a los crianceros moverse aún con relativa libertad y controlar con autonomía su patrón de reproducción económica y social. Este status quo sería rápidamente cuestionado y desestructurado. Entre la década de 1930 y 1940, en consonancia con la gran depresión del capitalismo a nivel internacional, la emergencia del nacionalismo y el viraje «hacia adentro» de las economías vernáculas, se produjo el cierre definitivo de la frontera entre Argentina y Chile, como corolario de políticas que buscaban la protección de los mercados nacionales. La consecuencia para los crianceros sería la restricción de la ganadería trashumante en dos aspectos: por un lado, cerró la comercialización con el histórico mercado de consumo en Chile y, por otro lado, limitó el ámbito de circulación de los veranadores a la franja argentina de la cordillera, la que, si bien continúo bajo la forma del contrabando por los innumerables boquetes cordilleranos, fue duramente afectada.

\section{De la ley de erradicación caprina ‘y de los crianceros? a la valoriza- ción cultural}

Durante la intervención provincial a cargo del Ing. Rosauer, se promulgó el Decreto-Ley No 505/1967 de erradicación caprina, que hirió fuertemente a los crianceros trashumantes. ${ }^{14}$ Bajo argumentos ecológicos de preservación del suelo, esta ley imponía onerosas penas económicas a la tenencia de chivos en tierras fiscales, con el propósito de desalentar la cría de cabras. Si tenemos en cuenta que para la época más del $85 \%$ de las situaciones dominiales eran «irregulares», es posible vi-

\footnotetext{
${ }^{14}$ El Decreto $N^{\circ} 505 / 1967$ perseguía la eliminación de la producción caprina mediante el cobro de tasas diferenciales a los productores fiscaleros en el pago de sus permisos de pastaje y la Ley 505/67 promovía la erradicación del caprino, principal sustento de los crianceros de ciertas áreas de pastoreo a los efectos de preservar la riqueza forestal (Río Negro, 09/04/ $2005)$.
} 
sualizar el dramático impacto de la medida para los crianceros. ${ }^{15}$ En este sentido, la problemática de la desertización como un tópico permanente en los debates sobre las políticas del desarrollo rural neuquino tiene este controvertido punto de partida, que atraviesa las siguientes décadas de 1980 y 1990, plegado a un discurso ecologista y ambientalista que identifica el deterioro medioambiental con los crianceros, en tanto obstáculos para la utilización alternativa por otros actores sociales, teniendo correlación con procesos de expansión capitalistas hacia estas áreas rurales del interior neuquino, otrora marginales (Bendini et al., 1993). En síntesis, este cúmulo de medidas evidencian la desconfianza y estigmatización que sufrieron los crianceros desde la llegada de los agentes del Estado nacional y que hacia fines de la década de los '60 alcanzó su paroxismo, por diversos factores: socio-culturales, debido al origen indígena y «chileno» de la trashumancia; geopolíticos, por los conflictos fronterizos con Chile; económicos, para reorientar la actividad hacia la consolidación de un mercado nacional; $y$, finalmente, por razones ecológicas vinculadas a la desertificación que generaba la ganadería caprina.

Desde las agencias de planificación estatal de Neuquén y del Estado nacional, especialmente el Consejo de Planificación y Acción para el Desarrollo (COPADE) y el Consejo Federal de Inversiones (CFI), ${ }^{16}$ prevalecía una visión de la actividad criancera como constitutiva del «subdesarrollo», de acuerdo con las coordenadas típicas del pensamiento económico estructuralista de la época. La superación del sistema productivo existente se visualizaba mediante la sustitución del caprino, principal responsable de la marginalidad económica y social; la incorporación de ga-

15 De acuerdo a un informe de situación de la Dirección de Tierras y Colonización de Neuquén el 89,71\% de los crianceros estaban en una «situación irregular». Ergo, en tierras fiscales. En el departamento Minas, el 93,41\%; en el departamento Chos Malal, el 83,72\% en el departamento Ñorquín y 88,42\% en el departamento Loncopué (AHPN. Informe de Tierras y Colonización, 1970).

${ }^{16} \mathrm{El}$ COPADE actuó como síntesis gubernamental de la concepción desarrollista, dominante en materia de políticas económicas hasta mediados de la década de 1970 en Argentina, en consonancia con los lineamientos del CFI a nivel nacional. El desarrollo era entendido a través de una planificación sistematizada y un Estado con fuerte incidencia en el delineamiento e instrumentación de las políticas económicas y sociales. El Estado se constituía, desde esta concepción, en un vector de modernización y la planificación en uno de sus pilares. El cerebro neuquino, institucionalizado por el Gobernador Felipe Sapag, actuaba bajo una lógica preponderantemente técnica que seguía los lineamientos de implantación de las políticas públicas de desarrollo en un sentido vertical de arriba hacia abajo, con un carácter marcadamente tecnocrático. 
nado ovino para la producción de fibras orientadas al mercado para exportación; la ruptura de la dinámica trashumante, considerada como una práctica irracional; y el desarrollo forestal como actividad económica eficiente que contribuiría a la preservación del medio ambiente. Al analizar los documentos de planificación elaborados por el COPADE se evidencia la caracterización de la región como sumida en un profundo grado de subdesarrollo con perspectivas de crecimiento económico y desarrollo humano fuertemente sombrías.

$\mathrm{Al}$ respecto, entre los elementos mencionados por la tecnocracia estatal se consignaba el bajo nivel de vida manifestado en todas sus dimensiones: deplorables indicadores de mortalidad, educativos, sanitarios, de vivienda, la economía de subsistencia y el fuerte éxodo de población ponían de manifiesto graves dificultades para lograr el desarrollo de la región en el corto y mediano plazo. Bajo este diagnóstico, se proponía una transformación radical de la estructura socioeconómica de la región que implicaba, en líneas generales, realizar una política de tabla rasa con los actores identificados como los responsables del «atraso» de la región, ergo, los crianceros, generando, a partir de allí, las bases para una modernización económica y social.

Son sintomáticos los objetivos explicitados en los planes de desarrollo de la época para la zona, donde se buscaba: «1) crear condiciones para pasar de una economía de subsistencia a una economía de mercado, 2) lograr el aprovechamiento racional de los recursos y 3) obtener un cambio de mentalidad en la población que sea favorable al desarrollo». ${ }^{17}$ La concepción política y técnica de pensar la pequeña ganadería trashumante como «irracional», producto del minifundio fiscal, es decir, debido a la «insuficiente extensión de las explotaciones para obtener una rentabilidad adecuada» ${ }^{18}$ y la inexistencia de mecanismos básicos de mercado inclinaban a la búsqueda de soluciones que significaban la erradicación de sujetos sociales considerados atávicos y su superación por los procesos de modernización, significando, llegado el caso «adjudicar la propiedad de las mismas a los productores más aptos, programar la reubicación de los productores que sea necesario desalojar». ${ }^{19}$

Las distintas consideraciones negativas transitaban diversas capas discursivas, que iban desde argumentos ecológicos hasta el darwinismo

${ }^{17}$ COPADE. (1970). Plan de Desarrollo. Zona Norte, Tomo I, p. 1.

${ }^{18}$ COPADE. (1970). Plan de Desarrollo. Zona Norte, Tomo I, p. 145.

${ }^{19}$ COPADE. (1970). Plan de Desarrollo. Zona Norte, Tomo I, p. 146. Destacado nuestro. 
social sobre los crianceros y su actividad, generando un cúmulo de sentidos donde la sospecha ante actores considerados insuficientemente argentinos, carentes de racionalidad económica, era la constante. A partir de esta época se acentuó la situación de pobreza extrema de los trashumantes, transformados en los «enemigos públicos» del campo neuquino. Un observador lúcido como el arqueólogo Jorge Fernández (1965), describía por esos años la «mala época» de los «rajadiablos» crianceros, en tono desesperante: «los crianceros-ganaderos neuquinos se encuentran en un momento que, para ellos, no es de crisis, sino de llana y franca pobreza, rayana en la miseria» (p. 34).

Figura 1. «La majada acercándose hacia la estación de Zapala», 1947

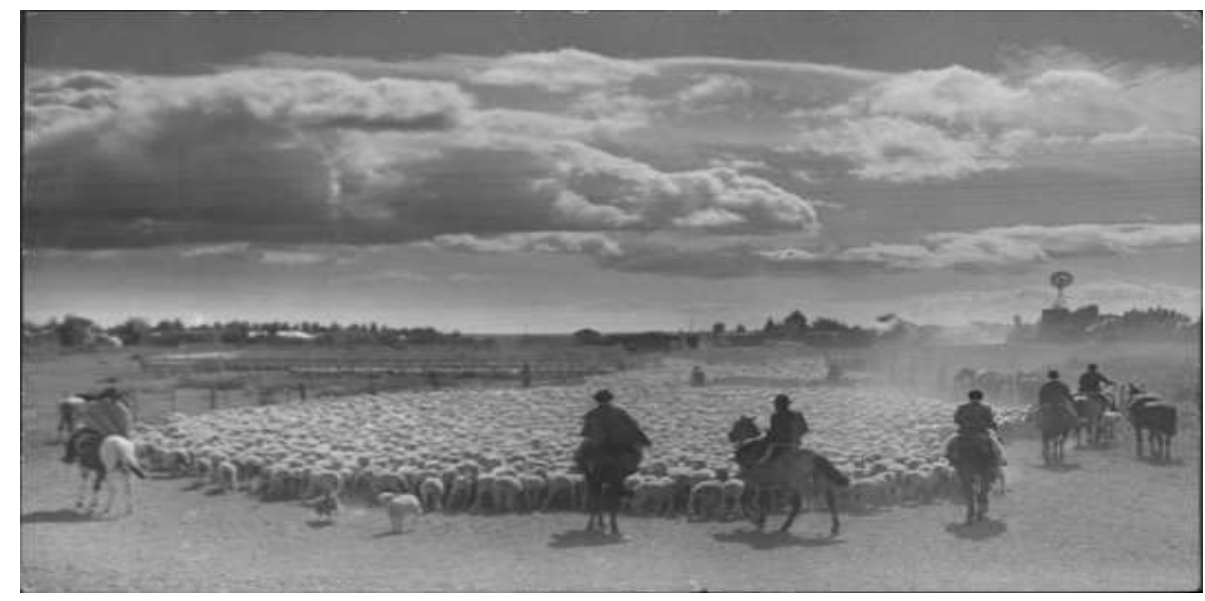

Fuente: Archivo General de la Nación

La alarmante situación social del interior rural neuquino comenzó a ocupar un lugar de privilegio en la agenda política provincial y nacional. Los indicadores sociales y económicos, visibilizados en la prensa gráfica, mostraban guarismos preocupantes, asociados a la caída en desgracia de la pequeña ganadería y a la ausencia prácticamente absoluta de infraestructura social. Así:

«las estadísticas sanitarias del norte de Neuquén son peores que las de Vietnam... Mientras el promedio nacional de mortalidad infantil es del 59 por mil, en el Neuquén llega a 112. El Neuquén figura en los puestos más lamentables en enfermedades producidas por la mi- 
seria, el abandono y el aislamiento. Son ellas: tuberculosis, brucelosis, hidatidosis, bocio, mal de Chagas». ${ }^{20}$

La revista Gente, a través de su editor Samuel Gelblung, publicaba: «Aquí viven argentinos, en pueblos desconocidos: Andacollo, Las Ovejas, Invernada Vieja, Varvarco, nunca vieron funcionar un motor. Ignoran que el hombre llegó a la luna. Muchos de ellos jamás vieron un auto. Están lejos de su propio país y del mundo...». ${ }^{21}$ En términos hiperbólicos se narraban las condiciones de miseria de los veranadores del Alto Neuquén. La ausencia de los mínimos contactos con el mundo moderno, como ver un automóvil o la llegada del hombre a la luna, eran considerados como el signo inequívoco de una situación de profundo subdesarrollo. Con el característico tono sensacionalista del semanario, se verificaba la ausencia de los básicos rudimentos del progreso material en ese espacio olvidado del territorio nacional. Se exclama que «Aquí viven argentinos...» $\mathrm{Y}$, sin embargo, «...el siglo XX no llegó». El quiebre de la actividad económica vinculada a la ganadería era uno de los factores explicativos clave, sumado a la carencia absoluta de infraestructura vial, sanitaria, educativa y habitacional, que completaban un cuadro de situación caracterizado por la miseria y el desamparo. Desde la prensa nacional y regional se hicieron eco de la situación y difundieron la crisis que se vivía en la provincia, particularmente en el norte neuquino.

A partir de ese momento el Estado neuquino, con los fondos ingresados en concepto de regalías energéticas, comenzó a desplegar un plan de rescate de la zona centro y norte, con el objetivo de revertir los pésimos indicadores sociales de la región. En ese marco, se llevó adelante un ambicioso plan de obra pública, basado en la construcción de la red provincial de caminos, rutas y puentes, modernos establecimientos educativos que eliminaron las tristemente célebres escuelas rancho, la implementación de un plan de salud modelo para el país y la construcción de cientos de viviendas. La intervención estatal a favor de la ganadería trashumante comenzó con la anulación de la ley de erradicación caprina y con programas tendientes a las mejoras sanitarias y técnicas de la actividad, con la construcción de mataderos y frigoríficos y la creación de asociaciones de fomento rural para propiciar la reunión cooperativa de los crianceros, buscando la eliminación de la intermediación comercial.

\footnotetext{
${ }^{20}$ Rio Negro, $17 / 06 / 1968$.

${ }^{21}$ Gente, (252), 21/05/1970.
} 
A partir de esta época la práctica de los crianceros trashumantes comenzó a ser considerada parte del patrimonio cultural provincial, junto con las cantoras del norte neuquino, la gastronomía popular en torno al chivo criollo y las festividades religiosas como San Sebastián. A partir de las últimas décadas del siglo XX se produjo, por parte de los poderes públicos, una celebración culturalista de la actividad que invisibiliza los avatares que sufrieron los crianceros trashumantes durante buena parte de la centuria y que estereotipa bajo la forma de un esencialismo tradicionalista, ligado a las manifestaciones del exotismo folclórico, sus aristas controvertidas, siendo probablemente la más importante la cuestión irresuelta de la propiedad de la tierra, donde aún continua la actividad desarrollándose mayoritariamente en propiedades fiscales.

Figura 2. «Niñas saliendo de su rancho en el Alto Neuquén», 1972

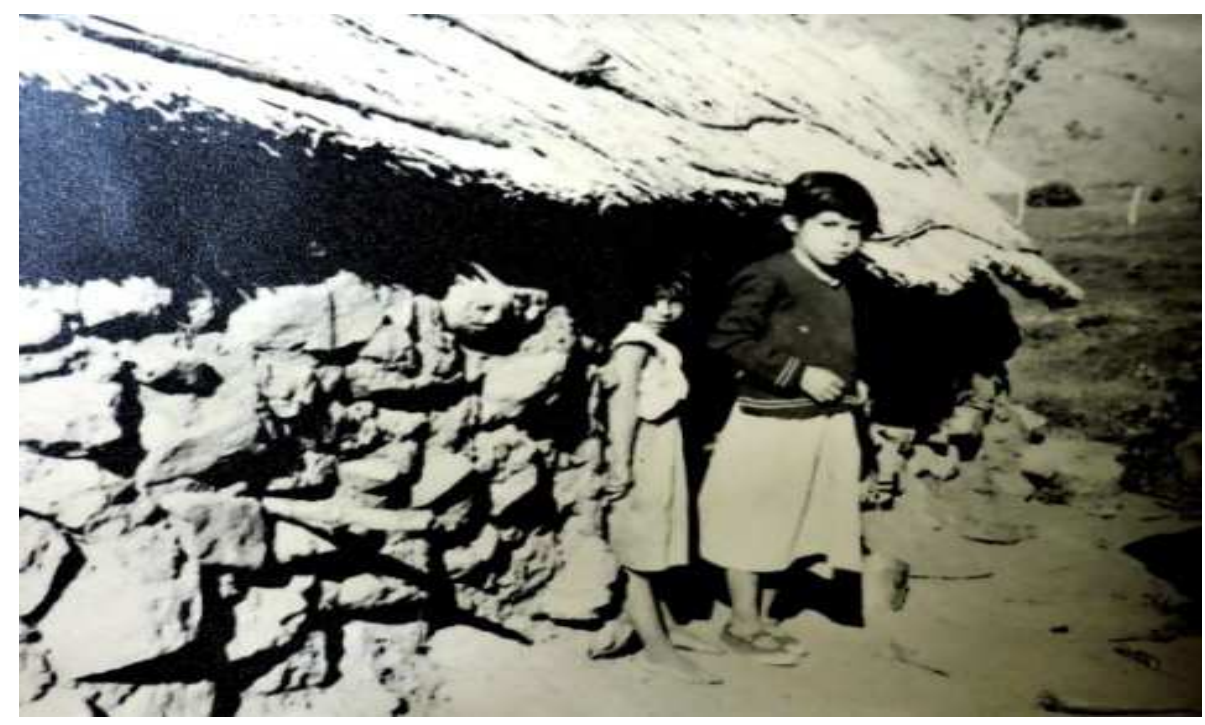

Fuente: Colección Dr. Antonio Gorgni - AHPN. 
Figura 3. Trashumancia en el siglo XXI

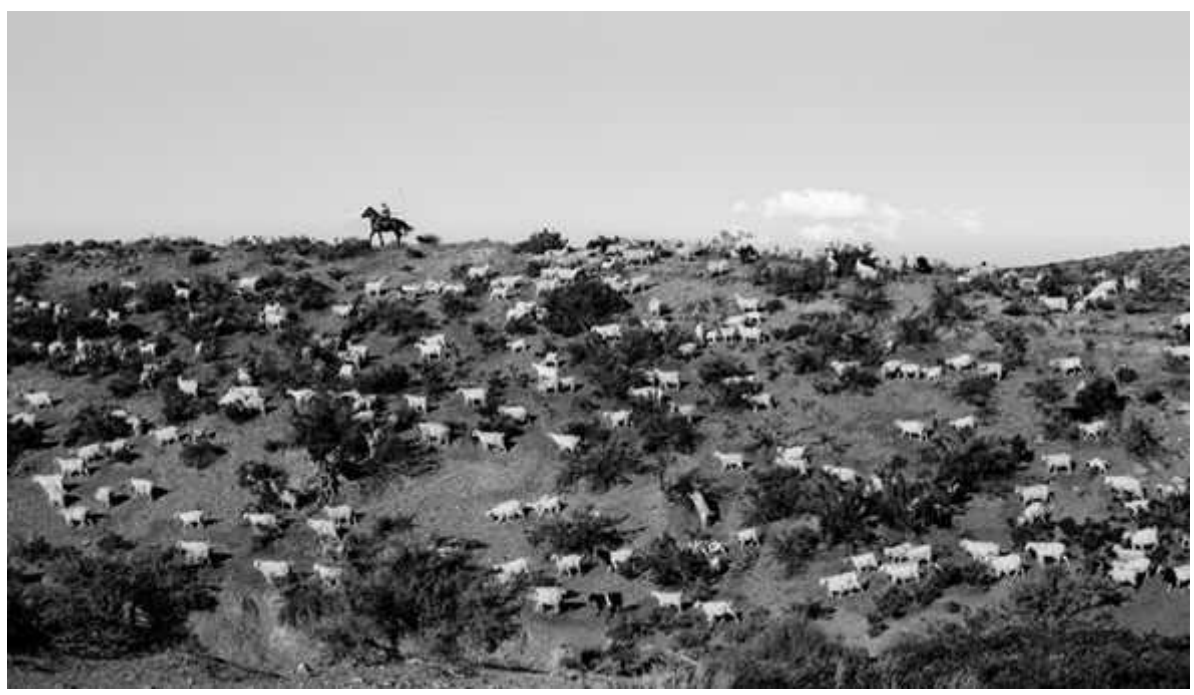

Fuente: Ph. Agustino Mercado.

\section{Consideraciones finales}

Resulta admirable la capacidad de lucha y persistencia de los crianceros frente a políticas cambiantes que pusieron en peligro la secular práctica de la trashumancia. A lo largo de este artículo hemos intentado, por un lado, situar la mirada en la dialéctica entre políticas frecuentemente hostiles hacia el universo sociocultural de los crianceros y la capacidad de agencia y adaptación de los mismos. Por otro lado, detenernos en el análisis de los desplazamientos discursivos en las representaciones sociales de los crianceros, en una parábola que transitó, desde una mirada estigmatizadora desde los poderes públicos, hasta la actual revalorización de su acervo cultural. Podemos concluir que el viento, el frío, la distancia y el olvido forjaron el temple de estos hombres y mujeres que permiten explicar su existencia en pleno siglo XXI. En la actualidad, lejos de ser una reliquia del pasado, la trashumancia muestra una enorme vitalidad. Prueba de ello lo constituye la obtención de la primera denominación de origen en Argentina del chivito neuquino, la sanción de la Ley $\mathrm{N}^{\mathrm{o}} 3016$ de Trashumancia, que busca preservar las tradicionales huellas de arreo, el creciente uso en la industria de la alta costura de las 
fibras de la lana mohair y cashmere y el interés que despierta en los turistas que observan atónicos el andar entreverado de hombres y animales surcando la Cordillera de los Andes. En los desafíos a futuro quedan pendientes dos problemáticas históricas: la cuestión ecológica vinculada al sobrepastoreo y la desertificación de los campos fiscales y la resolución definitiva de la tenencia y propiedad de la tierra. Las nuevas generaciones de crianceros darán una respuesta a estos interrogantes abiertos...

\section{Referencias bibliográficas}

Bandieri, S. Favaro, O. y Morinelli, M. (Eds.). (1993). Historia de Neuquén. Buenos Aires, Argentina: Plus Ultra.

Bandieri, S. (2005). Historia de la Patagonia. Buenos Aires, Argentina: Sudamericana.

Bandieri, S. y Blanco, G. (Coords.)(2007). Patagonia total. Antártida e Islas Malvinas. Buenos Aires, Argentina: BarcelBaires.

Bandieri, S. (2012). Más acá del Colorado... Historia regional y relaciones fronterizas en la norpatagonia argentina: el caso de Neuquén. Nuevo Mundo, mundos nuevos, (7), 1-25.doi: 10.4000/nuevomundo.63690.

Bendini, M., Tsakoumagkos, P. y Destéfano, B. (1985). El trabajo trasbumante en la Provincia de Neuquén. Neuquén, Argentina: UNCoCOPADE.

Bendini, M. y Tsakoumagkos, P. (1993). Campesinado y ganadería trasbumante en Neuquén. Buenos Aires, Argentina: La Colmena-Universidad Nacional del Comahue.

Bendini, M. Nogués, C. y Pescio, C. (1993). Medio ambiente y sujetos sociales: el caso de los cabreros trashumantes. Debate agrario, (17), 123-130.

Carbajal, L. (1985 [1906]). Por el Alto Neuquén. Ascensión al pico Domuyo. Neuquén, Argentina: Siringa Libros.

Daus, F. (1948). Trashumación de montaña en Neuquén. Buenos Aires, Argentina: Sociedad Argentina de Estudios Geográficos.

Duimich, L. y Lizárraga, F. (2017). Una aproximación a los sentidos de la neuquenidad (1956-2008), Identidades, (7), 33-43. 
Fernández, J. (1965). Contribución al conocimiento geográfico de la región del Alto Neuquén. IDIA, (207), 1-44.

García, N. (2008). El lugar del pasado en la construcción de una identidad. Neuquén, 1966-1976. Revista de Historia, (11), 131-146.

Goñi, R. (1987). Arqueología de sitios tardíos en el Valle del río Malleo, Provincia del Neuquén. Relaciones de la Sociedad Argentina de Antropología, Tomo 17-1, 37-49.

Onfray, M. (2016). Teoría del viaje. Poética de la geografía. Buenos Aires, Argentina: Taurus.

Perren, J. (2005). Cuando la resistencia es invisible a los ojos. Repertorios de acción en el Territorio Nacional del Neuquén (1885-1920). En S. Bandieri et al. (Dir.). Hecho en Patagonia. La historia en perspectiva regional, pp. 451-477. Neuquén, Argentina: Universidad Nacional del Comahue.

Quintero, S. (2002). Geografías regionales en la Argentina. Imagen y valorización del territorio durante la primera mitad del siglo XX. Scripta Nova. Revista electrónica de geografía y ciencias sociales, $V I$ (127). Recuperado de http://www.ub.es/geocrit/sn/sn-127.htm.

Olascoaga, M. (1974). Estudio Topográfico de La Pampa y Rio Negro. Buenos Aires, Argentina: Eudeba.

Silla, R. (2011). Colonizar argentinizando. Identidad, fiesta y nación en el Alto Neuquén. Buenos Aires, Argentina: Antropofagia.

Villalobos, S. (1989). Los pehuenches en la vida fronteriza. Santiago de Chile, Chile: Universidad Católica de Chile.

Yupanqui, A. (1948). Tierra que anda. Montevideo, Uruguay: Anteo. 